\title{
Arbor
}

\section{Flujos migratorios hacia Europa: actualidad y perpectivas*}

Anna Cabré, Andreu Domingo

Arbor CLXXII, 678 (Junio 2002), 325-344 pp.

\section{Introducción: la construcción europea y la visibilidad estadística}

De los 376 millones de habitantes que en 2000 registraba Eurostat como residentes en los quince países de la Unión Europea, aproximadamente 18,5 tenían nacionalidad extranjera, lo que representaba el $5 \%$ del total, entre ellos 13 millones eran de nacionalidad de países extracomunitarios, ascendiendo el porcentaje al 3,5\% del total, a esos datos se debería añadir una bolsa de inmigrantes no contabilizados de difícil estimación, pero que en todo caso en conjunto no rebasaría el $7 \%$ de la población residente en la Unión. Dicha población de nacionalidad extranjera se ha incrementado notablemente durante la década de los noventa a consecuencia de la aceleración de los flujos migratorios destinados a Europa, con alrededor de 700 mil de entradas anuales (Eurostat, 2000), aunque estos últimos datos deban interpretarse como una aproximación muy somera a los flujos reales, habiéndose señalado el aumento de los movimientos que escapan a cualquier registro estadístico. Aceleración, feminización e incremento de la clandestinidad han sido las tres características destacadas de los movimientos migratorios dirigidos a la Unión Europea durante la década de los noventa (Sopemi, 1999; Salt, 1999; Salt y otros, 2000; Sopemi, 1999).

Antes de proseguir con nuestro análisis debemos advertir que el primer obstáculo para el conocimiento y la previsión demográfica de las migraciones internacionales en Europa lo constituye la incertidumbre numérica. Las fuentes estadísticas para el estudio de las migraciones internacionales y de las características de la población de nacionalidad ex- 
tranjera residente en la Unión Europea son escasas, poco fiables y difícilmente comparables. Las principales causas para esas deficiencias hay que buscarlas tanto en las diferencias legislativas en la regulación de los flujos migratorios como en los dispares criterios de recuento y en la heterogeneidad en la calidad del mismo por lo que se refiere a las migraciones, a la que habrá que añadir la diversa definición tanto del estatuto de extranjero como el acceso a la nacionalidad en cada uno de los países para lo que se refiere al asentamiento de la población de nacionalidad extranjera. Todo ello contribuye a que nuestra imagen de los flujos migratorios dirigidos hacia la Unión Europea sea tan sólo una visión aproximativa y borrosa, estadísticamente hablando, que debería ser tratada con gran cautela, y a que las características de la población ya asentada, si bien mejor registrada, tenga que tener siempre en cuenta la distorsión del volumen que pueden representar aquellos que para la estadística siguen siendo invisibles: los no registrados.

La estadística, en un tema tan crucial como el de la inmigración internacional nos recuerda sus orígenes como ciencia del estado: la visión de los flujos migratorios adolece tanto de su novedad en un continente tradicionalmente emigratorio hasta mediados del siglo XX, como del propio proceso de construcción europeo. Hoy por hoy las series estadísticas de los diferentes países europeos reflejan con más fidelidad los cambios legislativos de cada uno de estos países en materia de extranjería y migraciones internacionales que los movimientos reales que se han producido durante el período considerado, poniendo además de manifiesto la falta de una política unitaria sobre migraciones y asentamiento de la población de nacionalidad extranjera que tiene su traducción directa en la escasa comparabilidad entre los datos disponibles. Así pues, resulta del todo aventurado prever el volumen de los futuros flujos migratorios, siendo necesaria una mirada retrospectiva para arriesgarse a predecir sino los efectivos que van a componer esos flujos, sí parte de las características sociodemográficas de los mismos y el papel que van a jugar en la evolución demográfica del futuro europeo.

\section{Migraciones y población de nacionalidad extranjera en Europa (1950-2000)}

La segunda mitad del siglo veinte certificó la conversión de la Europa Occidental en una zona de recepción de inmigración. Esa inversión en el sentido de los movimientos migratorios estuvo estrechamente relacionada con las transformaciones demográficas, económicas, y políticas de 
Europa. En 1950, los residentes de nacionalidad extranjera representaban un escaso $1,5 \%$ del total de la población, el aumento de los flujos y consiguientemente de la proporción de personas de nacionalidad extranjera conllevó un cambio en los orígenes de los migrantes así como en las características sociodemográficas de los mismos. A grandes rasgos, desde entonces podemos distinguir cuatro períodos: a) 1950-1973, de la posguerra hasta la crisis económica, con el desarrollismo de los años sesenta como pieza central; b) 1973-1982, el período correspondiente a la crisis económica; c) 1982-1992, el período de la recuperación económica; y d) 1993-2000 marcado por la toma de conciencia de las migraciones como asunto prioritario en la agenda política de la Unión Europea.

\section{a) 1950-1973: el desarrollismo}

Durante estos años, la inmigración de trabajadores constituyó el flujo más importante a tener en cuenta: hombres jóvenes, en edad activa y principalmente ocupados en el sector industrial fueron los protagonistas de dichos movimientos migratorios. En general, durante los años sesenta, de existir una política migratoria, cuando no se dejaba en manos de la iniciativa privada, consistió en la incentivación tanto en los países de origen como en los de destino, siendo el modelo del Gestarbaiten alemán el más extendido. "El trabajador invitado", procedía principalmente de los países mediterráneos europeos: portugueses, españoles, italianos, griegos y yugoslavos, aunque junto con ellos podíamos encontrar a magrebís, turcos, o personas procedentes de algún país de la Commonwealth para el Reino Unido. Siempre siguiendo la concepción del trabajador invitado, de esos inmigrantes que llegaban prioritariamente a Alemania, Francia, Suiza, Bélgica o Gran Bretaña, se esperaba que una vez transcurrida parte o la totalidad de su vida activa volvieran a sus países de orígenes. La evolución de los saldos migratorios (la resta de inmigración y emigración) de los quinquenios correspondientes a los años sesenta (Tabla 1 y Gráfico 1), muestra una clara dicotomía entre emisores y receptores de inmigración. A los países receptores anteriormente citados habría que añadir Suecia y Luxemburgo, destacando como el carácter positivo de dichos saldos es determinante en la evolución del crecimiento total de la población, si exceptuamos el caso de Gran Bretaña, donde incluso los saldos llegaron a ser negativos a partir del quinquenio 1965-1969. Para Dinamarca, Austria y Holanda el balance entre emigración e immigración durante este período es ligeramente positivo a favor de la inmigración sin que en cambio pueda compararse con los niveles 
alemanes o franceses. Por último, Irlanda presenta saldos negativos a consecuencia de la tradicional emigración transoceánica, mientras que en Finlandia la emigración a la vecina Suecia puede recordar los movimientos migratorios de los países mediterráneos a los países centrales de la Unión.

Junto con las migraciones de trabajadores, para este período de los años sesenta, no debemos olvidar tampoco los movimientos humanos producto del proceso de descolonización así como los asilados y refugiados. En el primer apartado deberemos destacar el poco más de un millón de personas que emigró de Argelia a Francia entre 1962 y 1963, una vez firmado el tratado de Evián. Sino tan numerosos de idéntico carácter fueron los movimientos sucedidos con la descolonización de Indonesia en el caso de Holanda o la del Congo en el caso de Bélgica. Por último, la partición de Europa en dos bloques y las tensiones propias de la guerra fría fueron la fuente de las corrientes más cuantiosas de refugiados y asilados, así por ejemplo, en 1956-57, tras el cierre de la frontera entre Hungría y Austria, se calcula que llegaron a esta última república más de 194 mil refugiados húngaros, del mismo modo, la Primavera de Praga de 1968 y la posterior ocupación soviética, produjeron aproximadamente unos 162 mil refugiados checos y eslovacos en los países de la Europa Occidental (Munz, 1995).

\section{b) 1973-1982: la crisis económica}

La crisis económica de los años setenta tuvo una especial repercusión en la ocupación en el sector industrial, y consecuentemente importantes consecuencias en los movimientos migratorios y en las políticas dirigidas tanto a la migración como a la población extranjera residente en cada uno de los países que habían destacado como receptores de inmigración. Una de las primeras medidas adoptadas para combatir el creciente desempleo fue orientada a la restricción de la llegada de nuevos flujos migratorios, a la vez que se incentivaba el retorno de los inmigrantes residentes. Las políticas de cariz claramente restrictivo se promovieron en nombre de la protección de la mano de obra autóctona. El resultado de tales medidas fue dispar: así, mientras para los países del sur de Europa el retorno de inmigrantes fue una realidad (observése como para todos ellos los saldos migratorios indican una recuperación especialmente significativa durante el quinquenio 1974-79) , y por ende las políticas pueden ser evaluadas como efectivas, para el resto de nacionalidades ese retorno no sólo no se produjo en el volumen deseado, sino que al final del 
período el número de inmigrantes procedentes de países terceros a la Unión Europea había crecido (aunque los flujos como puede inducirse de la evolución del saldo migratorio hubieran disminuido en comparación al período anterior). Además de cambiar los origenes de los flujos y la nacionalidad de la población extranjera, la estructura por sexo y edad se transformó radicalmente. El aumento de menores y mujeres puso de manifiesto la voluntad de asentamiento de la inmigración, acabando con el modelo del trabajador inmigrado identificado exclusivamente con jóvenes de sexo masculino.

Para entender tan contradictorio resultado hay que tener en cuenta la realidad histórica y política de los países emisores de inmigración. Por un lado Italia, España, Portugal y Grecia ofrecían un espacio social de retorno inexistente en el resto de países. En los tres últimos países se había vivido la caída de sendas dictaduras, iniciándose un proceso de transición democrática, y en los cuatro los años sesenta habían representado un salto económico cualitativo que, junto con el retraso de la toma de conciencia de la crisis económica, son factores a tener en cuenta en el retorno acaecido. Paralelamente, la falta de ese

TABLA 1. Saldo migratorio de los países de la Unión Europea, 1960-1999

\begin{tabular}{||ccccccccr||}
\hline & $1960-64$ & $1965-69$ & $1970-74$ & $1975-79$ & $1980-84$ & $1985-89$ & $1990-94$ & $1995-99$ \\
\cline { 2 - 8 } EU-15 & 0,6 & $-0,1$ & 0,6 & 0,8 & 0,2 & 1,3 & 2,9 & 1,8 \\
Alemania & 2,2 & 2,9 & 2,2 & 0,2 & 0,0 & 4,2 & 7,0 & 2,5 \\
Austria & 0,1 & 1,4 & 2,5 & $-0,4$ & 0,7 & 2,8 & 7,5 & 0,7 \\
Bélgica & 1,5 & 1,8 & 0,9 & 0,7 & $-0,7$ & 0,8 & 1,9 & 1,1 \\
Dinamarca & 0,2 & 0,2 & 1,3 & 0,4 & 0,2 & 1,2 & 2,0 & 3,0 \\
España & $-3,5$ & $-0,9$ & $-0,9$ & 0,8 & 0,0 & $-0,5$ & 0,4 & 1,1 \\
Finlandia & $-2,5$ & $-4,1$ & 0,3 & $-1,5$ & 0,8 & 0,5 & 1,8 & 0,8 \\
Francia & 6,5 & 1,9 & 2,2 & 0,6 & 1,0 & 0,9 & 1,3 & 0,7 \\
Grecia & $-4,9$ & $-4,1$ & $-2,8$ & 6,1 & 1,8 & 2,4 & 5,7 & 2,0 \\
Holanda & 0,3 & 0,8 & 2,0 & 2,6 & 1,0 & 1,9 & 2,7 & 1,9 \\
Irlanda & $-1,8$ & $-1,8$ & $-0,8$ & 0,1 & $-0,5$ & 0,0 & 1,9 & 2,1 \\
Italia & $-7,4$ & $-5,1$ & 3,4 & 3,1 & $-1,9$ & $-9,3$ & $-0,4$ & 4,2 \\
Luxemburgo & 6,5 & 2,6 & 11,1 & 3,9 & 1,1 & 5,9 & 10,5 & 9,9 \\
Portugal & $-8,7$ & $-19,1$ & $-5,1$ & 9,7 & 0,5 & $-4,5$ & $-1,3$ & 1,1 \\
Reino Unido & 1,1 & $-0,8$ & $-0,6$ & $-0,2$ & $-0,2$ & 1,1 & 1,3 & 2,3 \\
Suecia & 1,4 & 3,1 & 0,9 & 2,0 & 0,6 & 2,9 & 3,7 & 1,1 \\
\hline
\end{tabular}

Fuente: Eurostat, 2000 
espacio socioeconómico y político idóneo para el retorno en países terceros, se alió a los efectos contraproducentes de una política restrictiva retrasando los proyectos de retorno, adelantando los de migración en el país de origen, y promoviendo la reagrupación familiar en el país de destino.

El resultado final fue un importante cambio en la composición por nacionalidad de los flujos migratorios, en la estructura por sexo y edad de dichos movimientos, y en una creciente desregularización de aquellos que los protagonizaban, dando como fruto un aumento de la migración clandestina. A las migraciones de trabajadores deberemos añadir los movimientos como fruto de las descolonizaciones tardías en el caso de Angola y Mozambique para Portugal, y los de refugiados que huían de las dictaduras instaladas en el Cono Sur latinoamericano, de especial relevancia en España, y más tardíamente los resultantes del inicio de la descomposición del bloque oriental, como fueron los más de 250 mil polacos emigrados entre 1980 y 1981.

TABLA 2. Crecimiento natural de la población de los países de la Unión Europea, 1960-1999

\begin{tabular}{||rrrrrrrrr||}
\hline & $1960-64$ & $\mathbf{1 9 6 5 - 6 9}$ & $\mathbf{1 9 7 0 - 7 4}$ & $\mathbf{1 9 7 5 - 7 9}$ & $\mathbf{1 9 8 0 - 8 4}$ & $\mathbf{1 9 8 5 - 8 9}$ & $\mathbf{1 9 9 0 - 9 4}$ & $\mathbf{1 9 9 5 - 9 9}$ \\
\cline { 2 - 8 } EU-15 & 7,9 & 6,9 & 4,5 & 2,6 & 2,0 & 1,7 & 1,4 & 0,8 \\
Alemania & 6,0 & 4,1 & $-0,7$ & $-2,0$ & $-1,2$ & $-0,7$ & $-1,0$ & $-1,0$ \\
Austria & 6,0 & 4,3 & 1,1 & $-0,8$ & 0,0 & 0,2 & 1,4 & 0,6 \\
Bélgica & 4,9 & 3,1 & 1,7 & 0,6 & 0,8 & 1,0 & 1,7 & 1,0 \\
Dinamarca & 7,4 & 6,7 & 4,6 & 2,3 & $-0,6$ & $-0,3$ & 1,1 & 1,4 \\
España & 12,8 & 12,0 & 11,1 & 9,7 & 5,9 & 3,0 & 1,4 & 0,3 \\
Finlandia & 8,9 & 6,6 & 3,5 & 4,5 & 4,2 & 2,8 & 3,2 & 2,0 \\
Francia & 6,7 & 6,0 & 5,8 & 3,6 & 4,3 & 4,2 & 3,7 & 3,4 \\
Grecia & 10,3 & 9,9 & 7,4 & 6,8 & 5,0 & 1,6 & 0,6 & 0,0 \\
Holanda & 13,1 & 11,1 & 7,7 & 4,5 & 4,1 & 4,1 & 4,3 & 3,6 \\
Irlanda & 9,1 & 8,5 & 6,7 & 3,8 & 1,2 & 0,4 & 0,1 & $-0,6$ \\
Italia & 10,0 & 10,0 & 11,2 & 10,9 & 10,6 & 7,2 & 5,5 & 5,4 \\
Luxemburgo & 4,0 & 2,5 & $-0,3$ & $-0,6$ & 0,4 & 1,1 & 3,4 & 3,9 \\
Portugal & 13,3 & 11,6 & 9,4 & 8,3 & 5,5 & 2,8 & 1,1 & 0,6 \\
Reino Unido & 6,4 & 5,8 & 3,0 & 0,4 & 1,3 & 2,0 & 2,3 & 1,5 \\
Suecia & 4,5 & 4,7 & 3,4 & 1,0 & 0,3 & 1,5 & 2,9 & $-0,1$ \\
\hline \hline
\end{tabular}

Fuente: Eurostat, 2000 


\section{Flujos migratorios hacia Europa}

GRÁfICo 1: Componentes del crecimiento de la población de los países de la Unión Europea, 1960-1999
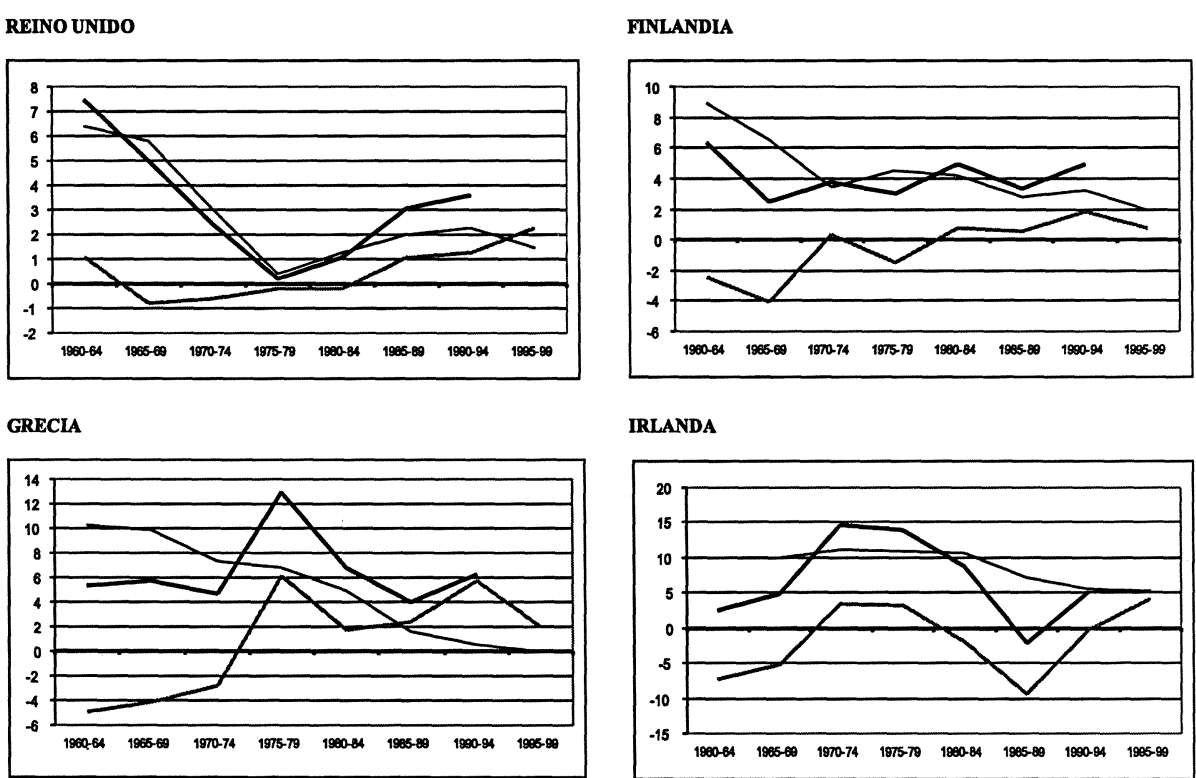

IRLANDA
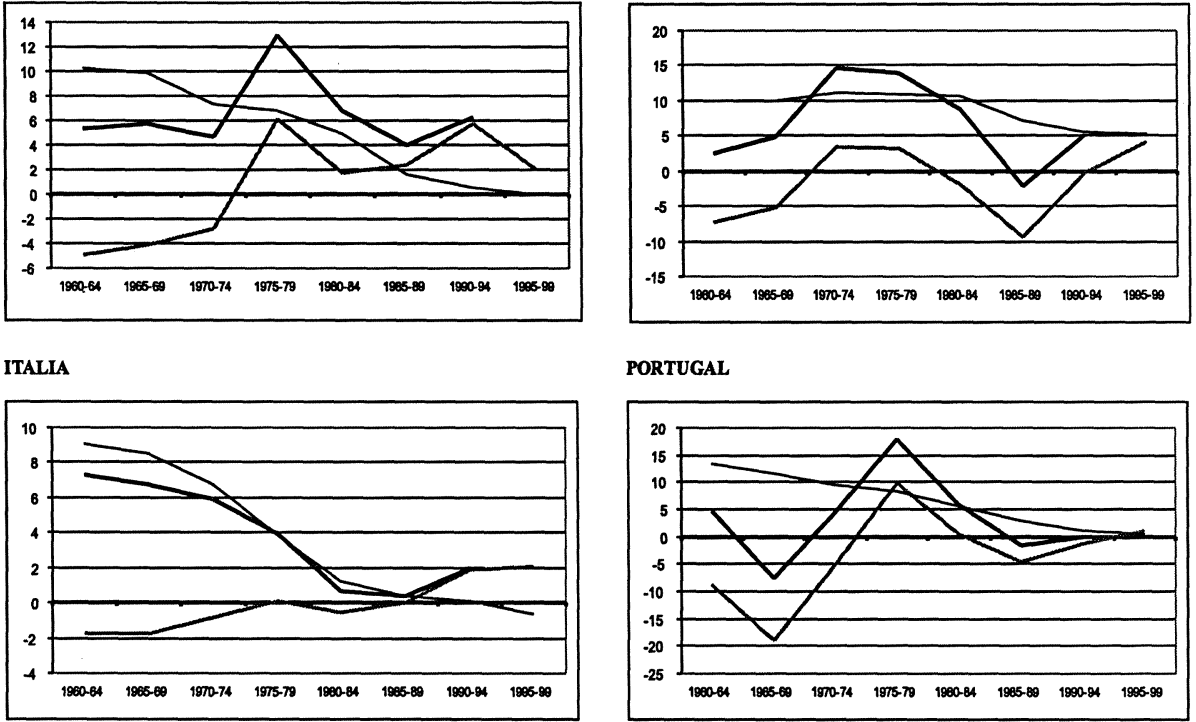

PORTUGAL
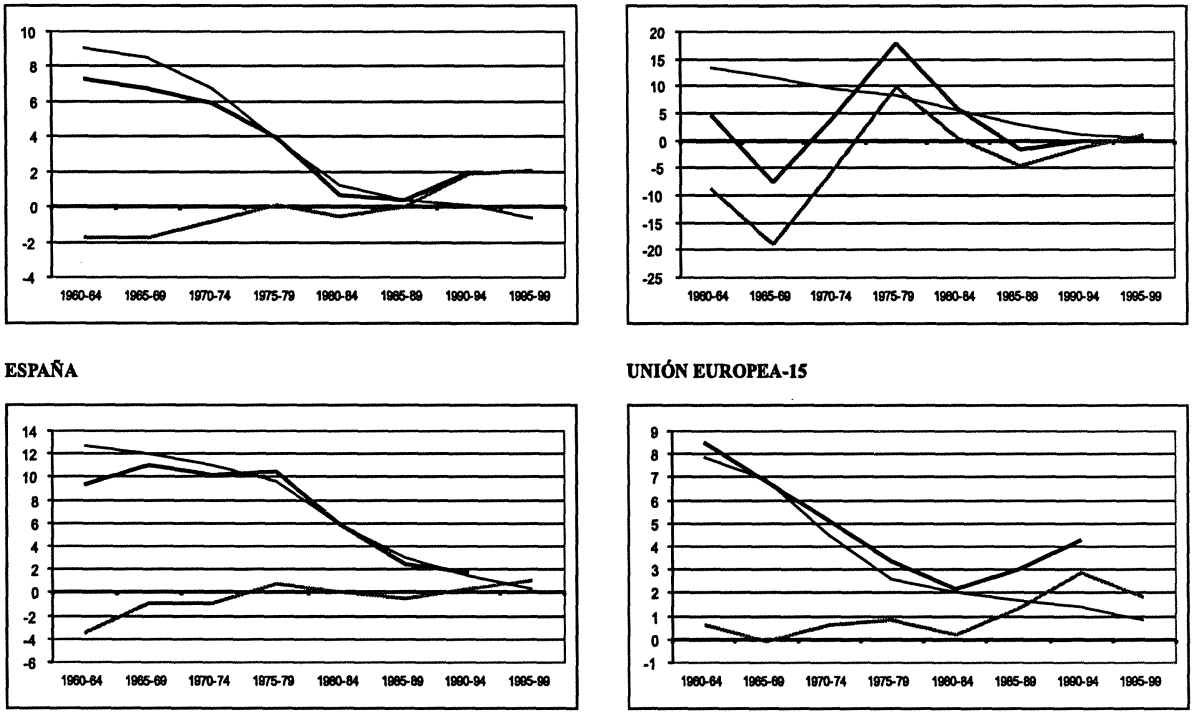

UNIÓN EUROPEA-15

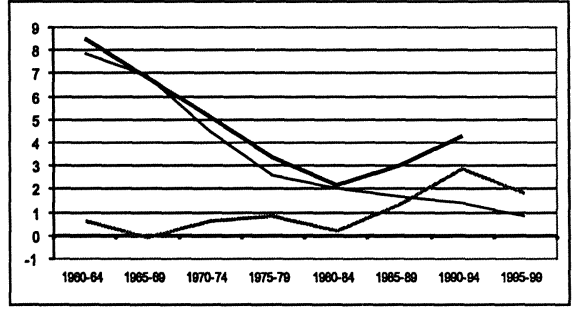

- Saldo migratorio - Crecimiento natural Creclmiento Total

Fuente: Tablas 1 y 2. 
GRÁFICO 1: Componentes del crecimiento de la población de los países de la Unión Europea, 1960-1999
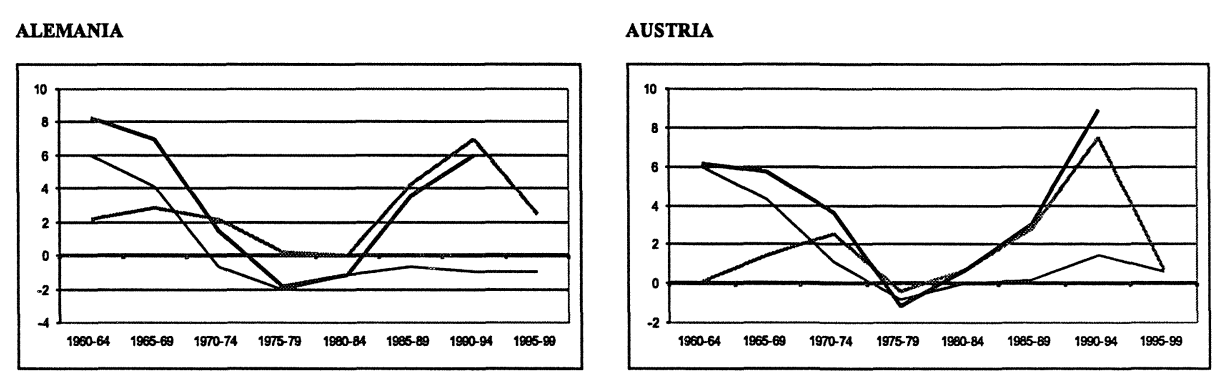

BELGICA

DINAMARCA
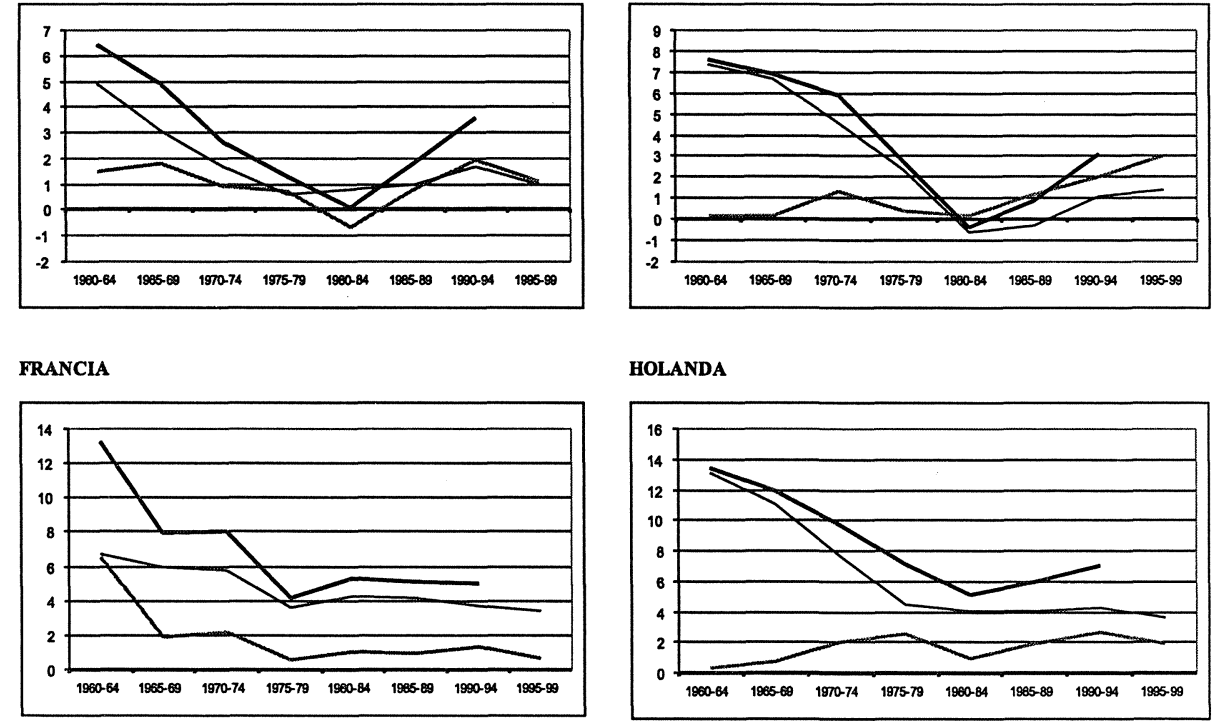

HOLANDA
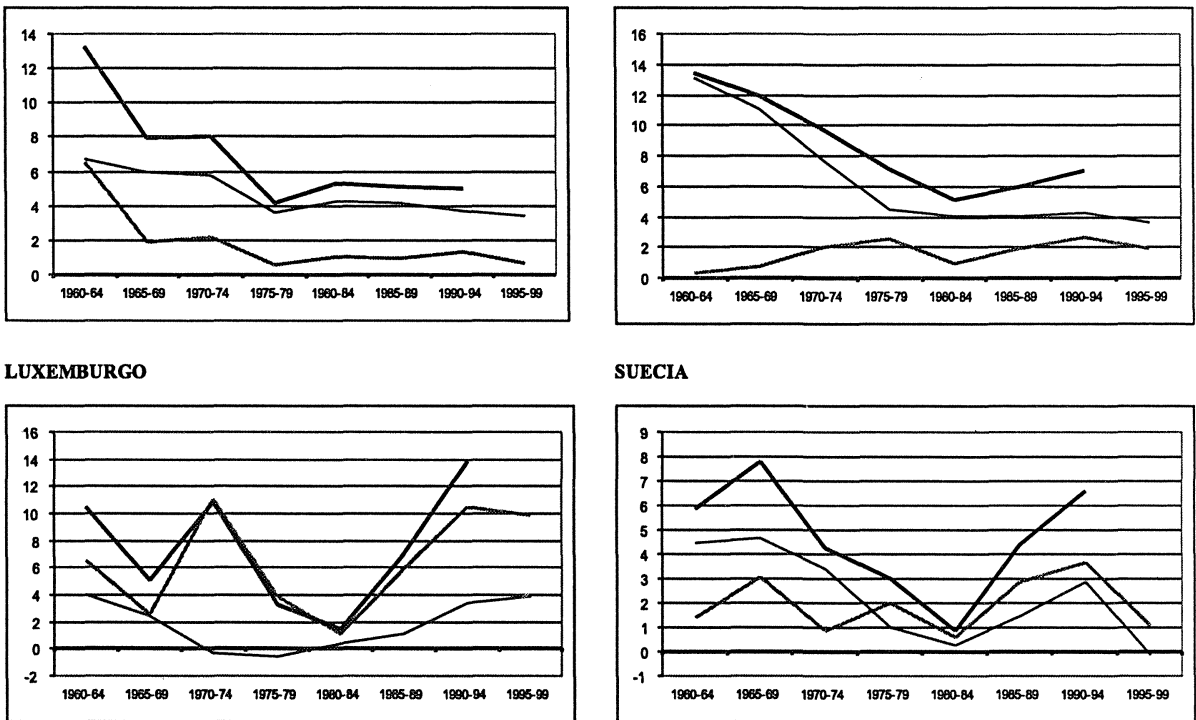

SUECIA

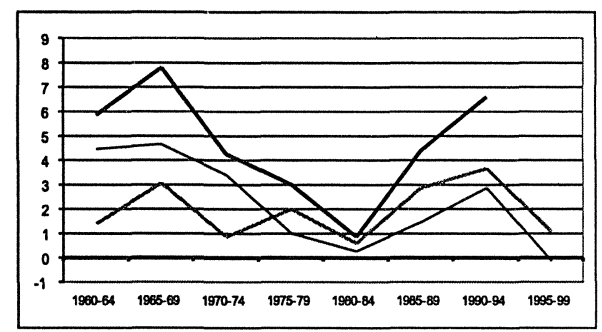

- Saldo migratorio - Creclmiento natural Crecimiento Total

Fuente: Tablas 1 y 2. 


\section{Flujos migratorios hacia Europa}

\section{c) 1983-1992: la recuperación económica}

Si bien las expectativas de substitución de la mano de obra empleada debida a la revolución de la emergente economía informacional no se produjeron en la medida de lo esperado, la recuperación de la crisis económica puso de manifiesto importantes cambios en las migraciones internacionales en Europa y no menos flagrantes contradicciones en las políticas migratorias. Por un lado, la demanda de mano de obra se generaba no ya en el sector industrial sino en el sector servicios que es el que experimentará a partir de entonces un mayor crecimiento, por el otro, las políticas de cada uno de los países miembros de la Unión Europea siguieron estando marcadas por la negativa experiencia de la crisis y ancladas en una visión proteccionista avivada por los efectos negativos de la globalización económica. Durante este período no sólo se incrementó la inmigración en los antiguos países receptores, sinó que además los países mediterráneos de la Unión Europea inviertieron el signo del saldo migratorio pasando de ser países eminentemente emigratorios a países de inmigración.

También a partir de entonces, el fenómeno migratorio empezó a configurarse como una pieza relevante en la construcción europea, afectando a las políticas nacionales sobre inmigración. A este respecto sirva de ejemplo el caso español, de todos es conocido como la Ley de extranjería de 1985 se enmarcó en la entrada de España en la Comunidad Europea en 1986, o como la regularización de 1991 (lo mismo que la italiana de 1990), es incomprensible sin la referencia al tratado de Schengen sobre libre circulación de personas pertenecientes a los países firmantes, iniciado en 1985 y definitivamente firmado en junio de 1991. En la voluntad política de Schengen se insiste en favorecer la movilidad de los trabajadores de los países comunitarios, la de trabajadores cualificados de países terceros, y la migración de retorno de ciudadanos miembros de la comunidad o de colectivos étnicos considerados pertenecientes a estados miembros de la Comunidad (en clara alusión a Alemania y Grecia). Mientras que se recomiendan todos los esfuerzos dirigidos a frenar la migración de trabajadores no cualificados de países terceros si no se trata de ocupaciones estacionales (con mención explícita para España e Italia), a los demandantes de asilo (con el argumento de que son inmigrantes económicos) y por fin, se incita a la expulsión de los inmigrantes llamados sin papeles (ilegales, irregulares o indocumentados).

Durante este período las migraciones de refugiados crecieron espectacularmente debido en su mayor parte por los efectos del colapso de los regímenes comunistas en los países del Este. Así, en 1989-90, más de 300 
mil búlgaros de ascendencia turca huyeron, aunque con posterioridad retornaron unos 120 mil (Munz, 1995). Con la caída del muro de Berlín y el proceso de unificación alemana, Alemania inició una política de retorno étnico, con la nacionalización inmediata de los ciudadanos soviéticos de ascendencia germánica, los llamados ausslieder (alemanes del Volga y prusianos principalmente), caso parecido al de Grecia, registrándose tan sólo en 1990 más de 100 mil entradas, y en 1991 flujos de una media alrededor de 20 mil personas mensuales para Alemania. También durante este período es necesario tener presente los refugiados del conflicto de los Balcanes, si bien la mayoría de los más de cinco millones de personas desplazadas lo hicieron dentro de las fronteras de la antigua República de Yugoslavia, siendo Alemania el país de la Unión Europea que más refugiados acogió. Episódicamente deberemos tener en cuenta además las oleadas procedentes del éxodo albanés, que en el verano de 1990 alcanzó su punto álgido y del que Italia ha sido el principal receptor. A excepción de Gran Bretaña y Holanda la década de los noventa inaugura una drástica restricción en la concesión de permisos para refugiados en todos los países europeos, registrándose descensos del $80 \%$ a Austria, del $78 \%$ en Suecia, del $81 \%$ en Alemania, y del $52 \%$ en Dinamarca tan sólo para el año 1992.

\section{d) 1993-2000: consolidación de la Unión Europea}

Como ya se ha señalado en la introducción la década de los noventa ha destacado por la aceleración de los movimientos migratorios, la feminización propiciada tanto por el reagrupamiento familiar como por la demanda del sector servicios, y la creciente clandestinidad. Observando el Gráfico 1, veremos como todos los países de la Unión Europa sin excepción registran saldos migratorios positivos, sobrepasando o recuperando para el primer quinquenio niveles semejantes a los de los años sesenta en países que habían sido tradicionalmente receptores de inmigración como Alemania o Bélgica, y confirmando el cambio de tendencia apuntado en el período anterior para los países mediterráneos que sin embargo siguen registrando efectivos relativamente inferiores. Por otro lado, es característico también al conjunto de los países de la Unión el protagonismo que el saldo migratorio adquiere en el cómputo global del crecimiento de la población.

La creciente llegada de flujos migratorios juntamente con el papel esencial que juegan en el crecimiento total de la población de cada uno de los países que componen la Unión Europea, ha hecho que la década de los 
noventa plantee de forma acuciante el diseño de una política migratoria conjunta. El tratado de Amsterdam y la reunión del Consejo de Europa celebrada en Tampere en 1999, marcan sin duda un cambio en la sensibilidad europea frente a la política migratoria, expresando la necesidad de acercar las diferentes legislaciones nacionales en materia de extranjería y desarrollar una política común tanto en lo que se refiere a los flujos de migrantes económicos como al derecho de asilo.

\section{Migraciones internacionales y población de nacionalidad extranjera en la Unión Europea a las puertas del siglo XXI}

Si observamos en la Tabla 3 y el Gráfico 2, los componentes de la tasa de crecimiento de la población de los quince países de la Unión Europea para 1999, vemos cómo el saldo migratorio se confirma como un elemento determinante del crecimiento total, llegando a contrarrestar el crecimiento natural negativo de países como Alemania (-0,9 por mil), Suecia $(-0,7$ por mil), Italia $(-0,6$ por mil), Grecia $(-0,1$ por mil), o Austria $(-0,0$ por mil). Para el resto de países, exceptuando Francia y Finlandia, el saldo migratorio ha significado más de la mitad del crecimiento total de la población, destacando España, donde el crecimiento debido al saldo migratorio representa un $83 \%$ de total, el Reino Unido con un 69\%, o Bélgica con un $64 \%$. En conjunto, el saldo migratorio positivo de 711.400 personas registrado en 1999 representó un $73 \%$ del crecimiento de la población experimentado por la Unión Europea con un total de 989.200 habitantes más que el año anterior.

Si de la observación de los flujos pasamos a la observación de los stocks de población (ver Tabla 4, y Gráficos 3 y 4), es decir, si cambiamos la óptica de las migraciones a la población extranjera ya asentada veremos como persiste una clara dicotomía entre los países que tradicionalmente fueron receptores de migración y los países anteriormente emigratorios, especialmente en términos relativos (Gráfico 4), comparando el porcentaje que las personas de nacionalidad extranjera representan sobre el total de la población.

En cifras absolutas, y a mucha distancia los más de 7 millones de extranjeros residentes en Alemania se significan sobre el resto de países, incluso sobre los 3 millones censados en Francia o los 2 millones estimados para el Reino Unido. A este propósito debemos insistir en cómo, a parte de la lógica diferencia en el tamaño de la población de cada uno de los países, la legislación sobre el acceso a la nacionalidad es determinante en la presencia de la población extranjera. En cifras relativas, por en- 
GRÁFICO 2. Componentes de la tasa de crecimiento de la población de la Unión Europea, 1999

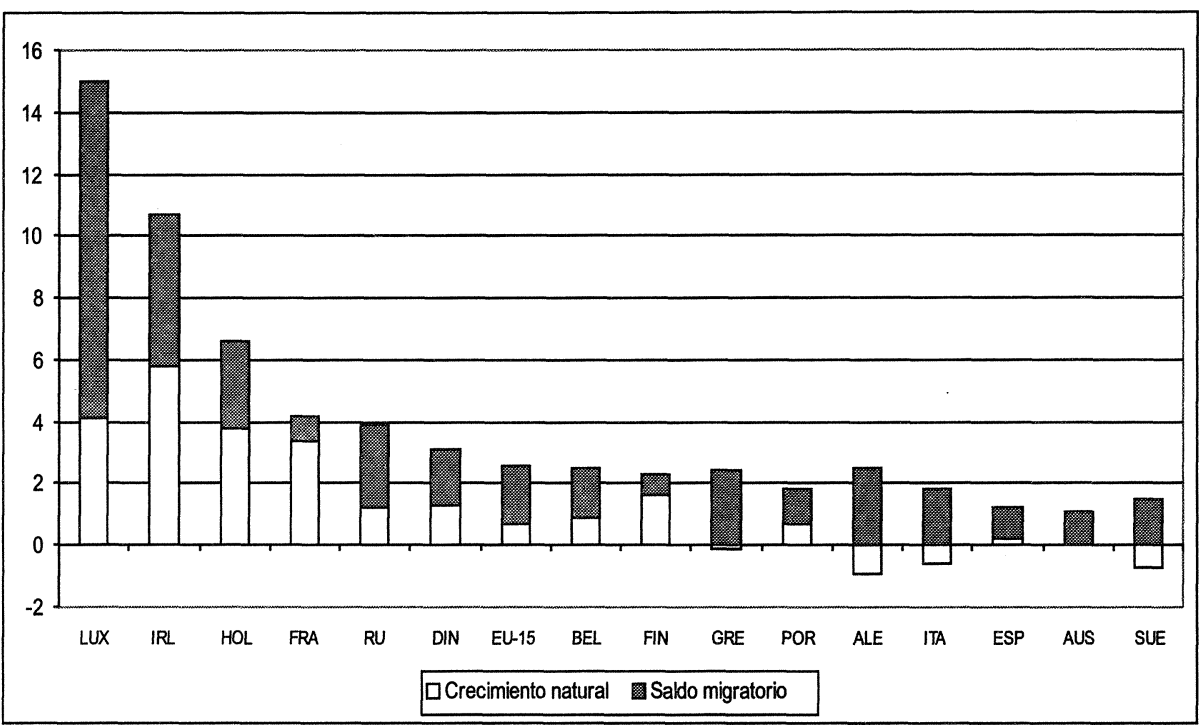

Fuente: Eurostat, 2000.

TABLA 3. Componentes de la tasa de crecimiento de la población de la Unión Europea, 1999

\begin{tabular}{||cccc|}
\hline EU-15 & $\begin{array}{c}\text { Crecimiento } \\
\text { Natural }\end{array}$ & $\begin{array}{c}\text { Saldo } \\
\text { Migratorio }\end{array}$ & $\begin{array}{c}\text { Crecimiento } \\
\text { Total }\end{array}$ \\
\cline { 2 - 4 } & 0,7 & 1,9 & 2,6 \\
Alemania & $-0,9$ & 2,5 & 1,6 \\
Austria & 0,0 & 1,1 & 1,1 \\
Belgica & 0,9 & 1,6 & 2,5 \\
Dinamarca & 1,3 & 1,8 & 3,1 \\
España & 0,2 & 1,0 & 1,2 \\
Finlandia & 1,6 & 0,7 & 2,3 \\
Francia & 3,4 & 0,8 & 4,2 \\
Grecia & $-0,1$ & 2,4 & 2,3 \\
Holanda & 3,8 & 2,8 & 6,6 \\
Irlanda & $-0,6$ & 1,8 & 1,2 \\
Italia & 5,8 & 4,9 & 10,7 \\
Luxemburgo & 4,1 & 10,9 & 15,0 \\
Portugal & 0,7 & 1,1 & 1,8 \\
Reino Unido & 1,2 & 2,7 & 3,9 \\
Suecia & $-0,7$ & 1,5 & 0,8 \\
\hline
\end{tabular}

Fuente: Eurostat, 2000. 
cima de la media de la Unión, que recordemos se situaba alrededor del $5 \%$, encontramos en lugares destacados a Luxemburgo (34,9\%), Austria (9\%), Alemania (8,9\%), y Bélgica (8,3\%), en el extremo opuesto aparecen los países mediterráneos junto con Finlandia e Irlanda (también tradicionalmente emigratorios), de este modo Grecia tan sólo registraba un $1,5 \%$ de población de nacionalidad extranjera, Portugal un 1,7\%, España el $2 \%$, e Italia el $2,2 \%$.

Gráfico 3. Población de nacionalidad extranjera en los países de la Unión Europea, Cifras absolutas, 1 de enero de 2000

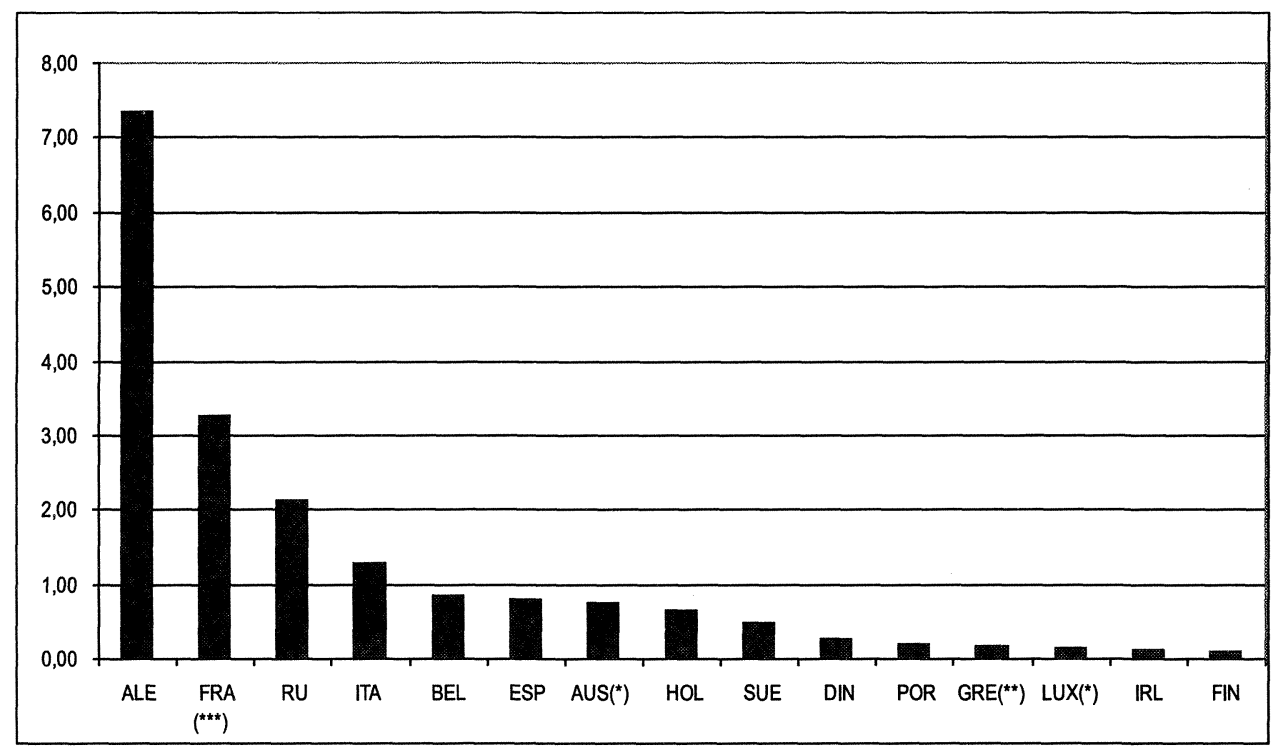

Fuente: Tabla 4.

La dicotomía entre el norte y el sur de la Unión Europea respecto a las migraciones internacionales y el asentamiento de la población de nacionalidad extranjera no se limita a los efectivos relativamente reducidos que aparecen en los países meridionales, sino que también se ha destacado tanto el diferente origen de las corrientes migratorias, y consecuentemente de la nacionalidad de los residentes asentados, como en el modo de integración de dicha población.

La diferencia en los volúmenes y el origen de los migrantes ha llevado a algunos autores a considerar la existencia de un subsistema mediterráneo dentro del sistema migratorio europeo (Massey y otros, 1998), mientras que 
GRÁfICo 4. Porcentaje de población de nacionalidad extranjera en los países de la Unión Europea, 1 de Enero de 2000

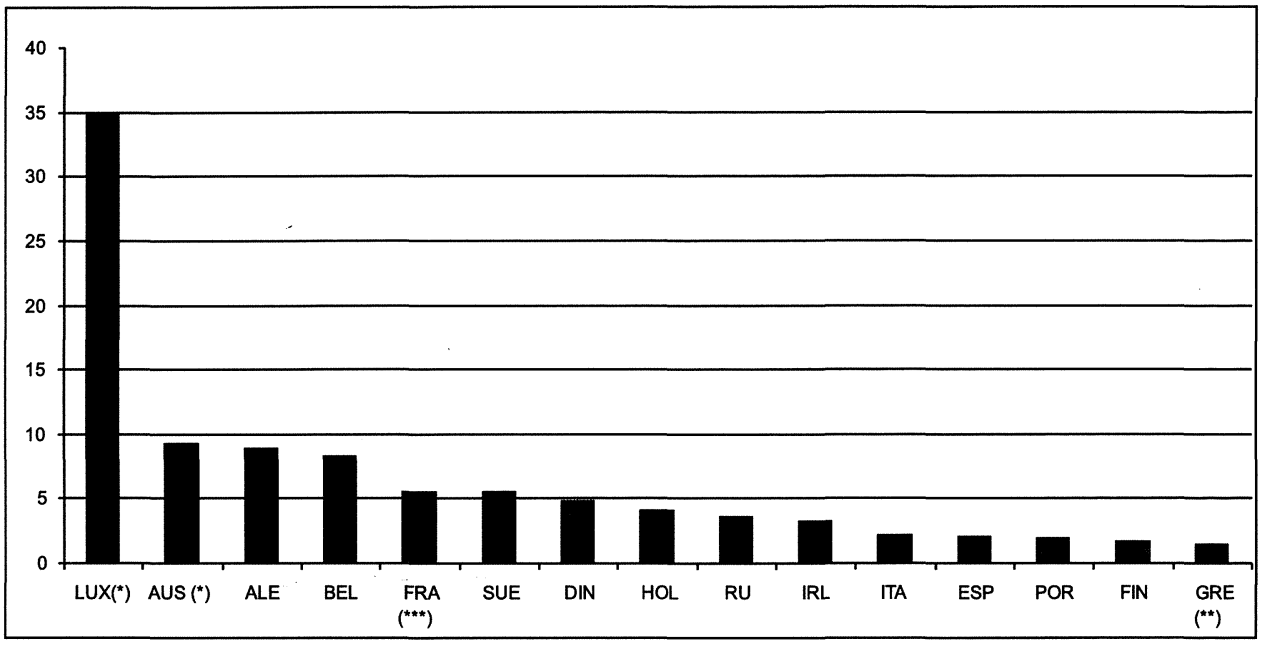

Fuente: Tabla 4.

${ }^{*}$ ) correspondiente a 1 de enero de 1998.

$\left.{ }^{* *}\right)$ correspondiente a 1 de enero de 1997.

$(* * *)$ correspondiente al Censo de 1999, INSEE.

otros señalan razones geopolíticas, económicas y demográficas como explicación de dicha especificidad (Baldwin-Edwards y Arango, 2000).

Por lo que se refiere al origen de la población extranjera en cada uno de los países de la Unión, observando el gráfico 5, para los 13 países de los que disponemos información desagregada, vemos como efectivamente la distribución continental es muy desigual. Por un lado en países como Alemania, Bélgica, Luxemburgo, o la propia Suecia, la población extranjera de nacionalidad europea representa más de la mitad de todos los efectivos, siendo la inmigración de los países del Este especialmente significativa en Alemania, Dinamarca, Finlandia o Suecia, mientras que en Irlanda y Luxemburgo es la inmigración procedente del resto de los países de la Unión la que explica por si sola ese peso aplastante del continente europeo. Por otro lado encontramos aquellos países como España o Portugal, donde la población de la Unión Europea con tener una representación importante, casi el $40 \%$ en España, y una cuarta parte en Portugal, los ciudadanos de algún país africano en primer lugar y americano en el segundo han ido aumentando su representación, hasta situarse en porcentajes iguales o superiores a los del conjunto del continente Europeo, Grecia e Italia por razones estrictamente geográficas conjugan 
TABLA 4: Población de nacionalidad extranjera a 1 de Enero de 2000

\begin{tabular}{|c|c|c|c|c|c|c|c|c|c|c|}
\hline \multirow[b]{2}{*}{ Alemania } & \multicolumn{2}{|c|}{ Total pob. Estran. \% sobre total } & \multirow{2}{*}{$\begin{array}{c}\mathrm{UE} \\
1.858 .672\end{array}$} & \multirow{2}{*}{$\begin{array}{c}\text { Resto Europa } \\
4.071 .639\end{array}$} & \multirow{2}{*}{$\begin{array}{l}\text { África } \\
300.611\end{array}$} & \multirow{2}{*}{$\begin{array}{c}\text { Asia } \\
823.092\end{array}$} & \multirow{2}{*}{$\begin{array}{l}\text { América } \\
205.373\end{array}$} & \multirow{2}{*}{$\begin{array}{c}\text { Oceanía } \\
10.033\end{array}$} & \multirow{2}{*}{$\begin{array}{c}\text { Apátridas } \\
18.032\end{array}$} & \multirow{2}{*}{$\begin{array}{c}\text { No consta } \\
56.139\end{array}$} \\
\hline & 7.343.591 & 8,9 & & & & & & & & \\
\hline Anstria $(*)$ & 753.528 & 9,3 & - & - & - & - & - & - & - & - \\
\hline Bélgica & 853.369 & 8,3 & 563.556 & 97.702 & 153.356 & 19.047 & 18.744 & 648 & 316 & 0 \\
\hline Dinamarca & 256.276 & 4,8 & 53.195 & 104.008 & 23.871 & 55.524 & 9.808 & 1.110 & 8.721 & 39 \\
\hline España & 801.329 & 2,0 & 312.203 & 40.771 & 213.012 & 66.922 & 166.709 & 1.013 & 582 & 117 \\
\hline Finlandia & 87.680 & 1,7 & 16.328 & 43.843 & 7.791 & 13.813 & 3.649 & 495 & 1.256 & 505 \\
\hline Francia $(* * *)$ & 3.263.186 & 5,5 &. & - & - & - & & - & - & - \\
\hline Grecia (**) & 161.148 & 1,5 & 45.020 & 52.412 & 13.237 & 27.884 & 19.996 & 1.242 & 0 & 1.357 \\
\hline Holanda & 651.532 & 4,1 & 195.886 & 137.494 & 149.764 & 62.368 & 36.484 & 3.168 & 6.776 & 59.592 \\
\hline Irlanda & 126.533 & 3,3 & 92.209 & - & - & & 8.044 & - & - & 26.280 \\
\hline Italia & 1.270 .553 & 2,2 & 148.506 & 349.664 & 411.492 & 236.369 & 120.898 & 3.154 & 470 & 0 \\
\hline Luxemburgo (*) & 147.700 & 34,9 & 131.410 & - & - & - & - & - & - & - \\
\hline Portugal & 190.898 & 1,9 & 52.429 & 4.285 & 89.518 & 7.890 & 35.987 & 516 & 273 & 0 \\
\hline Reino Unido & 2.121 .000 & 3,6 & 805.000 & 133.958 & 277.000 & 559.042 & 252.000 & 87.000 & 1.000 & 6.000 \\
\hline Suecia & 487.175 & 5,5 & 177.430 & 153.333 & 27.726 & 84.140 & 31.814 & 2.171 & 5.337 & 5.224 \\
\hline
\end{tabular}

Fuente: Cronos, Eurostat.

(*) correspondiente a 1 de Enero de 1998.

$\left.{ }^{* *}\right)$ correspondiente a 1 de enero de 1997.

(***) correspondiente al Censo de 1999, INSEE. 
una creciente población de personas procedentes de los países del Este con la presencia de población americana y africana. En conjunto podemos resumir diciendo que la diferencia en los orígenes depende tanto de la historia de cada uno de los países receptores que mantienen vínculos especiales con los emisores como por la proximidad geográfica, sin que a nuestro entender sean la razón substantiva que permita hablar de un subsistema mediterráneo.

Junto con la especificidad diferencial de los orígenes de los inmigrantes y el tamaño relativamente reducido de los flujos, también se ha señalado como en el sur de Europa la irregularidad ha sido desde el principio una constante asociada a la importancia del trabajo sumergido, en comparación con los países del septentrionales de la Unión Europea. Por último, la especificidad de los países mediterráneos, a parte de la situación geográfica, destacan características de tipo económico y demográfico.

Entre las características económicas, se subraya el desarrollo tardío entre los años sesenta y los ochenta, el peso de los sectores económicos abiertos al exterior como el turismo, el transporte marítimo y la pesca, o la aludida importancia de la economía informal. En el capítulo demográfico, que es el que nos interesa, se ha señalado el rasgo común de una baja fecundidad y el envejecimiento acelerado de la población como conjunción de la baja fecundidad y el alargamiento de la esperanza de vida (Baldwin-Edwards y Arango, 1999). Pero si bien es cierto que comparten estos rasgos no constituyen la causa de la especificidad de las migraciones internacionales que reciben. La especificidad de los flujos migratorios en los países del Sur de la Unión Europea, a nuestro parecer, debe comprenderse dentro de la especificidad de su evolución demográfica reciente, marcada por la intensidad de los cambios registrados en una coyuntura de reestructuración económica. De este modo, el descenso de la fecundidad, el retraso en la emancipación de los jóvenes y el alargamiento de la esperanza de vida, se dieron el los países mediterráneos con un particular retraso cronológico y una espectacular intensidad, siendo en sus inicios esa evolución por lo que se refiere a los primeros dos fenómenos una respuesta demográfica adaptativa a la crisis económica. Es dentro de ese entramado demográfico donde debemos situar la peculiar situación de la inmigración internacional y su incremento progresivo.

\section{Previsiones de futuro}

Durante las últimas décadas del siglo XX, el aumento de la población de la Unión Europea se ha debido no tanto a la conjunción de la dinámi- 


\section{Flujos migratorios hacia Europa}

GRÁFICO 5. Distribución porcentual de la población de nacionalidad extranjera por agrupaciones continentales, 2000

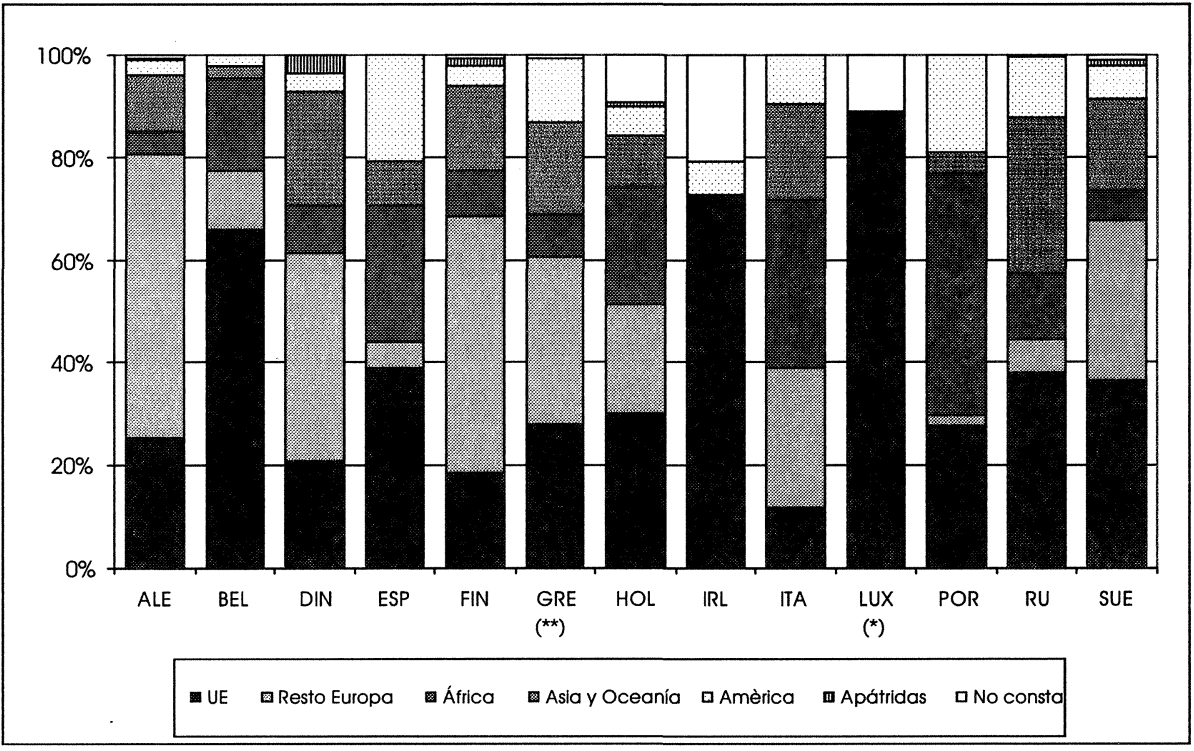

Fuente: Tabla 4.

ca demográfica, cuanto a la ampliación política de la Unión. Demográficamente hablando, el futuro próximo estará marcado por la creciente contribución de la migración en el crecimiento de la población europea, tanto es así que la consideramos el eje central de lo que hemos llamado Sistema Complejo de Reproducción (Cabré, Domingo y Menacho, 2002).

Sin embargo, el motor de esos movimientos migratorios no hay que buscarlo en la evolución demográfica de los países de la Unión Europea (caracterizados por la baja fecundidad, el alargamiento de la esperanza de vida y su consecuente envejecimiento), ni en el contraste con unos vecinos que si bien están reduciendo de forma significativa su fecundidad presentan estructuras de edad jóvenes y muy jóvenes. Las razones de los movimientos migratorios hay que buscarlas en el campo de lo económico, en el desarrollo desigual y el abismo de condiciones de vida que se dan entre países emisores y países receptores de la migración.

A partir de los años setenta hemos asistido a la difusión, con diversa cronología e intensidad para cada uno de los países que componen la Unión, del proceso que algunos autores han llamado Segunda transición demográfica (Van de Kaa, 1987, y 1999). Una vez concluida la transición demográfica en todos y cada uno de estos países, y tras una época dora- 
da para la nupcialidad y la fecundidad que dio lugar al baby boom de los sesenta, se asistió a un descenso continuado e intenso de la fecundidad, así como a una transformación de las formas familiares estrechamente relacionada con la igualación de los roles entre hombres y mujeres, paralelamente se asistió a un importante alargamiento en la esperanza de vida, que ha influido definitivamente en la redefinición de la construcción social de las edades.

En los países del sur de la Unión Europea esos cambios se iniciaron en la década de los setenta coincidiendo con la reestructuración económica. Más tarde, pero con mucha más intensidad. Del mismo modo, la conversión tardía de los países mediterráneos en países inmigratorios, anuncia una creciente aceleración de la intensidad de la inmigración en los mismos, con el telón de fondo de la convergencia demográfica europea. En estos momentos, en estos países están entrando en el mercado de trabajo los jóvenes pertenecientes a las generaciones relativamente vacías nacidas a partir del descenso de la fecundidad, esos mismo jóvenes que retrasaron su emancipación y que han protagonizado un espectacular avance en los niveles de instrucción, especialmente por lo que se refiere a las generaciones femeninas. Las expectativas de ocupación de estos jóvenes y de sus familias abren la puerta a la complementariedad en la integración de jóvenes inmigrantes en un mercado de trabajo segmentado. Al mismo tiempo, el potencial de integración de la mujer en el mercado de trabajo, junto con la generalización de las familias de doble ingreso genera una oferta creciente de empleo en el sector de servicios dedicado al trabajo doméstico y al cuidado de personas mayores o menores, que ya ahora está siendo ocupado por mujeres inmigradas de nacionalidad extranjera cuando no son las propias madres de los jóvenes padres y madres las que facilitan la conciliación de un proyecto reproductivo y el proyecto laboral de sus descendientes. Con todo, esa situación especialmente aguda en los países del Sur, donde la ayuda familiar sigue siendo primordial, a corto y medio plazo será insostenible, debido al envejecimiento de esas mismas generaciones femeninas que hoy en día cuidan de sus propias madres y nietos, aumentando aún más la demanda de externalización de esos servicios. Si a ello añadimos el fuerte potencial de reagrupación familiar de la población de nacionalidad extranjera asentada en estos países, y al mantenimiento de las desigualdades económicas entre los países desarrollados y los países en vías de desarrollo, entenderemos porqué los flujos migratorios seguirán creciendo de forma importante.

La inmigración se configura como complemento demográfico a la inversión intensiva en el capital humano efectuada por los europeos: el alargamiento de la esperanza de vida ha permitido alargar también el perío- 


\section{Flujos migratorios hacia Europa}

do que llamamos juventud, intensificando la instrucción, posponiendo la formación de nuevas familias y por ende reduciendo la fecundidad, al mismo tiempo que se efectuaba una verdadera revolución generacional en el papel de la mujer. Aunque, a corto plazo, si las expectativas de crecimiento económico son buenas es lógico augurar una recuperación de la fecundidad en países como España o Italia que actualmente siguen ostentando los niveles más bajos de la Unión Europea, esa recuperación no alcanzará los niveles extremadamente altos de los años sesenta y, lo que es más importante, será paralela al incremento de la inmigración.

El elemento clave del futuro de las migraciones en Europa, sigue siendo la legislación: de ella depende el modo de integración de esos nuevos europeos que se incorporarán en el futuro a nuestro mercado de trabajo, a nuestra dinámica demográfica $\mathrm{y}$, en definitiva, a nuestra sociedad. Como hemos visto, al periodificar la evolución de las migraciones en Europa, las políticas restrictivas de los años setenta, no sólo no consiguieron reducir el número de los flujos, sino que los acrecentaron. Las políticas restrictivas que actualmente están en vigor, actúan a nivel individual en el deterioro de las condiciones de vida de las personas inmigradas, y a nivel colectivo profundizan en un proceso de dualización que tiende a la estratificación étnica de la estructura social, con graves consecuencias para la cohesión social de la Unión Europea.

\section{Referencias bibliográficas}

BALDWIN-EDWARDS, y ARANGO, JOAQUIN (1999) Immigrants and the Informal Economy in Southern Europe. London: Frank Cass.

CABré, Anna, Domingo, Andreu i Menacho, Teresa (2002) «Demografía y crecimiento de la población española durante el siglo XX». En Mediterráneo Económico, núm 1, Monográfico: Pimentel Siles, MANUEl (Coord.). Procesos Migratorios, economía y personas., pp.121-138. Almería: Caja rural intermediterránea. Cajamar.

EUROSTAT (2000) Statistiques sociales européénnes. Démographie. Luxemburgo: Commission Européenne.

MASSEY, Dougals S. y otros (1998) Worlds in Motion. Understanding International Migration at the End of the Milenium. Oxford: Clarendon press Oxford.

MÜNZ, RAINER (1995), "Where did they all come from? Typology and geography of European mass migration in twentieth century", EAPS, IUSSP (Eds.), Evolution or Revolution in European Population. European Population Conference, Milano 1995. Milano: Franco Agneli, pàgs. 95-154.

SALT, JoHN (1999) Current Trends in International Migration in Europe. Brussels: Council of Europe. Mimeo.

Salt, John, Clarke, James, y Sandra SchmidT (2000) Patterns and trends in international migration in Western Europe. Brussels: Eurostat, European Comission. 


\section{Anna Cabré, Andreu Domingo}

344

SOPEMI (1999) Tendances des migrations internationales. Rapport Annuel 1999. Paris: OCDE.

VAN DE KAA, DiRK J. (1987) «Europe's Second Demographic Transition». En Population bulletin., vol. 42, 1, March 1987.

VAN DE KAA, DIRK J. (1999) «Without Maps and Compass? Toward a New European Transition Project». En European Journal of Population, (15): 309-316. 